\title{
Impact of age, age at diagnosis and duration of diabetes on the risk of macrovascular and microvascular complications and death in type 2 diabetes
}

\author{
Sophia Zoungas • Mark Woodward • Qiang Li • Mark E. Cooper • Pavel Hamet • \\ Stephen Harrap • Simon Heller • Michel Marre • Anushka Patel • Neil Poulter • \\ Bryan Williams • John Chalmers • for the ADVANCE Collaborative group
}

Received: 4 March 2014 / Accepted: 8 August 2014 / Published online: 17 September 2014

(C) Springer-Verlag Berlin Heidelberg 2014

\begin{abstract}
Aims/hypothesis Data are inconsistent regarding the associations between age, age at diagnosis of diabetes, diabetes duration and subsequent vascular complications.

Methods The associations between age (or age at diagnosis), diabetes duration and major macrovascular events, all-cause death and major microvascular events were examined in 11,140 patients with type 2 diabetes randomly allocated to intensive or standard glucose control in the Action in Diabetes and Vascular Disease: Preterax and Diamicron Modified Release Controlled Evaluation (ADVANCE) trial. Rates were calculated by 5 year baseline age (or age at diagnosis) and
\end{abstract}

Electronic supplementary material The online version of this article (doi:10.1007/s00125-014-3369-7) contains peer-reviewed but unedited supplementary material, which is available to authorised users.

S. Zoungas $\cdot$ M. Woodward $\cdot$ Q. Li $\cdot$ A. Patel $\cdot$ J. Chalmers The George Institute for Global Health, University of Sydney, PO Box M201, Missenden Road, Camperdown,

Sydney, NSW 2050, Australia

\section{S. Zoungas}

School of Public Health and Preventive Medicine, Monash

University, Melbourne, VIC, Australia

M. Woodward

Department of Epidemiology, Johns Hopkins University, Baltimore, MD, USA

\section{E. Cooper}

Baker IDI Heart and Diabetes Institute, Melbourne, VIC, Australia

P. Hamet

Research Centre, Centre hospitalier de l'Université de Montréal,

Montreal, QC, Canada

\section{S. Harrap}

The Royal Melbourne Hospital, University of Melbourne,

Melbourne, VIC, Australia diabetes duration strata. Risks were estimated using Cox models adjusted for treatment assignment and $\mathrm{HbA}_{1 \mathrm{c}}$.

Results The mean age $( \pm \mathrm{SD})$ was $65.8 \pm 6.4$ years, age at diagnosis was $57.8 \pm 8.7$ years and diabetes duration was $7.9 \pm 6.4$ years. Diabetes duration was associated with the risk of macrovascular events (HR 1.13 [95\% CI 1.08, 1.17]), microvascular events $(1.28[1.23,1.33])$ and death $(1.15$ $[1.10,1.20])$ whereas age (or age at diagnosis) was only associated with the risk of macrovascular events (1.33 [1.27, $1.39])$ and death $(1.56[1.48,1.64])$. No interaction was observed between diabetes duration, age and the risk of macrovascular events or death (both $p>0.4$ ). However, an

\section{S. Heller}

University of Sheffield and Sheffield Teaching Hospitals National Health Service Foundation Trust, Sheffield, UK

M. Marre

Hôpital Bichat-Claude Bernard and Université Paris 7, Paris, France

N. Poulter

International Centre for Circulatory Health, National Heart and Lung Institute, Imperial College, London, UK

B. Williams

Institute of Cardiovascular Science, University College, London, UK

S. Zoungas $(\bowtie)$

The George Institute for Global Health, PO Box M201, Missenden

Road, Camperdown, NSW 2050 Sydney, Australia

e-mail: szoungas@georgeinstitute.org.au 
interaction was observed between diabetes duration, age and the risk of microvascular events $(p=0.002)$, such that the effects of increasing diabetes duration were greatest at younger rather than older age.

Conclusions/interpretation In patients with type 2 diabetes, age or age at diagnosis and diabetes duration are independently associated with macrovascular events and death whereas only diabetes duration is independently associated with microvascular events and this effect is greater in the youngest patients.

Keywords Age $\cdot$ Age at diagnosis of diabetes $\cdot$ Duration of diabetes $\cdot$ Macrovascular complications $\cdot$ Microvascular complications $\cdot$ Mortality $\cdot$ Type 2 diabetes

\section{Abbreviations \\ ADVANCE Action in Diabetes and Vascular Disease: Preterax and Diamicron Modified Release Controlled Evaluation \\ UKPDS UK Prospective Diabetes Study}

microalbuminuria [7]. These data suggested a complex interplay between the effects of age and age at diagnosis on different vascular beds, with the authors proposing some effect of the unquantified period of hyperglycaemia prior to diagnosis.

The Action in Diabetes and Vascular Disease: Preterax and Diamicron Modified Release Controlled Evaluation (ADVANCE) trial examined the effects of intensive glucose control and blood pressure lowering on vascular complications and death in a broad range of people with established type 2 diabetes from around the world $[8,9]$. The purpose of the present analysis was to examine the separate effects of age or age at diagnosis and duration of diabetes, and any potential interaction, on the risk of macrovascular and microvascular events and all-cause mortality in a contemporary cohort with type 2 diabetes.

\section{Methods}

Study design and participants ADVANCE was a factorial randomised controlled trial evaluating the effects of intensive blood glucose control and blood pressure lowering on vascular outcomes among people with type 2 diabetes. A detailed description of the design has been published previously [10]. In brief, 11,140 individuals with type 2 diabetes aged 55 years and older, and at elevated risk of cardiovascular disease as indicated by a history of major macrovascular or major microvascular disease, a duration of diabetes of at least 10 years or one additional risk factor for cardiovascular disease, were enrolled from 215 centres in 20 countries. There were no participant inclusion or exclusion criteria based on prior levels of glycaemic control. Eligible participants were randomly assigned either to an intensive glucose control regimen based on treatment with gliclazide modified release (aiming for an $\mathrm{HbA}_{1 \mathrm{c}}$ level of $\leq 6.5 \%$ or $48 \mathrm{mmol} / \mathrm{mol}$ ) or to a standard glucose control regimen based on the local guidelines of participating countries. In a factorial design, participants were also randomly allocated to either a fixed combination of perindopril and indapamide $(4 \mathrm{mg} / 1.25 \mathrm{mg})$ or matching placebo, after a 6 week active run-in period on perindopril and indapamide $(2 \mathrm{mg} / 0.625 \mathrm{mg})$. Approval for the trial was obtained from each centre's institutional review board and all participants provided written informed consent.

Demographic and clinical variables Demographic and clinical variables at baseline were collected as described previously [10]. Age or age at diagnosis, and diabetes duration (calculated as baseline age minus age at diagnosis), were considered in 5 year strata.

Outcomes The main outcomes of this study were macrovascular events (cardiovascular death, non-fatal 
myocardial infarction or non-fatal stroke), death from any cause, and microvascular events. Microvascular events consisted of new or worsening nephropathy (development of macroalbuminuria, defined as a urinary albumin:creatinine ratio of $>300 \mu \mathrm{g}$ of albumin per milligram of creatinine [33.9 $\mathrm{mg} / \mathrm{mmol}]$, or doubling of the serum creatinine level to at least $200 \mu \mathrm{mol} / 1[2.26 \mathrm{mg} / \mathrm{dl}]$, the need for renalreplacement therapy, or death due to renal disease) or new or worsening retinopathy (development of proliferative retinopathy, macular oedema or diabetes-related blindness or the use of retinal photocoagulation therapy). All these events were reviewed and validated by an independent endpoint adjudication committee.

Statistical analysis All 11,140 participants were included in the analyses. Differences in variables at baseline between subgroups of the study population were tested using linear regression models for continuous risk factors and logistic regression models for binary risk factors. Spearman correlations were used to examine the correlation between the key variables. Follow-up time for each participant was calculated as time from registration date to date of event or date of censoring. Cox proportional hazard models were used to relate age or age at diagnosis and diabetes duration (as continuous variables) to the study outcomes using a two-step approach. Only the first event for each outcome was included in the analysis. In the first step, crude rates and risk models adjusted for randomised treatments (glucose control and blood pressure lowering) were calculated. In the second step, models were further adjusted for baseline $\mathrm{HbA}_{1 \mathrm{c}}$ levels. An interaction between the effects of age and diabetes duration was tested by adding an interaction term to the relevant Cox model. The cumulative incidence of macrovascular and microvascular events was also estimated using Fine and Gray's test where all-cause death was considered as a potential competing event [11]. Sensitivity analyses were conducted to examine: (1) the effect of adjustment for potential confounders that included sex, systolic blood pressure, BMI, lipids, smoking status, prevalent microvascular or macrovascular disease, renal function and urine albumin:creatinine ratio; (2) further adjustment for mean $\mathrm{HbA}_{1 \mathrm{c}}$ level before the index event; and (3) the effect of excluding participants with prevalent macrovascular or microvascular disease at baseline depending on the specific study outcome. A $p$ value $<0.05$ was taken to indicate statistical significance. All analyses were performed using SAS software, version 9.2 (SAS Institute, Cary, NC, USA).

\section{Results}

The baseline characteristics of the study population by 5 year strata of age and diabetes duration are shown in Tables 1 and 2, respectively. Overall, the mean $( \pm \mathrm{SD})$ age of the cohort was $65.8 \pm 6.4$ years and the age at diagnosis was $57.8 \pm 8.7$ years (Table 1), with $21 \%, 18 \%, 22 \%$ and $39 \%$ of patients reporting their age at diagnosis as $\leq 50,>50-55,>55-60$ and $>60$ years, respectively. The mean $( \pm \mathrm{SD})$ diabetes duration was $7.9 \pm$ 6.4 years, with $43 \%, 27 \%, 18 \%$ and $12 \%$ of patients reporting a diabetes duration of $\leq 5,>5-10,>10-15$ and $>15$ years, respectively (Table 2 ). The mean diabetes duration of the 5 -year age strata increased linearly from the youngest to the oldest but only varied by 1.5 years across the age groups ( $p$ for trend $<0.0001$, Table 1 ). The mean age of the groups by 5 -year diabetes duration strata was very similar, except for the group with the longest diabetes duration ( $>15$ years) who were on average only $1.2-1.5$ years older than the groups with shorter diabetes duration $(\leq 15$ years) (Table 2$)$. By contrast, the mean age at diagnosis of the group with the longest diabetes duration ( $>15$ years) was significantly lower than that of the groups with shorter diabetes duration ( $p$ for trend $<0.0001$, Table 2). Age, age at diagnosis and diabetes duration were all significantly correlated $(p<0.0001)$, with the strongest correlations evident for age and age at diagnosis (Spearman correlation coefficient 0.69 ), and diabetes duration and age at diagnosis (Spearman correlation coefficient 0.65 ).

Macrovascular events and death After base adjustment for randomised treatments and further adjustment for baseline $\mathrm{HbA}_{1 \mathrm{c}}$ level, age, age at diagnosis and diabetes duration were all associated with risks of macrovascular events and all-cause death (all $p<0.001$; Tables 3 and 4, Fig. 1a-f). For each 5 year increase in age (or age at diagnosis), the multiple adjusted risks of macrovascular events and all-cause death were increased by $33 \%$ and $56 \%$, respectively (Tables 3 and 4 ). For each 5 year increase in duration of diabetes, the multiple adjusted risks of macrovascular events and all-cause death were increased by $13 \%$ and $15 \%$, respectively, when accounting for age (Table 3 ), or increased by $49 \%$ and $78 \%$, respectively, when accounting for age at diagnosis (Table 4). Compared with the effects of a $1 \mathrm{SD}$ increase in diabetes duration on macrovascular events and all-cause death, which allows some direct comparison of relative effects, the effects of a $1 \mathrm{SD}$ increase in age and age at diagnosis were markedly greater (Electronic Supplementary Material [ESM] Tables 1 and 2).

When the components of the macrovascular outcome (fatal and non-fatal myocardial infarction or fatal and non-fatal stroke) were examined separately, the associations were consistent (ESM Table 3).

When the base models were adjusted for multiple potential confounding covariates (sex, systolic blood pressure, BMI, lipids, smoking status, prior microvascular disease or macrovascular disease, renal function and urine albumin:creatinine ratio) the associations were slightly attenuated but remained significant (ESM Table 4). When these 
Table 1 Baseline characteristics by 5 year age strata

\begin{tabular}{|c|c|c|c|c|c|c|}
\hline \multirow[t]{2}{*}{ Characteristic } & \multicolumn{5}{|l|}{ Age (years) } & \multirow[t]{2}{*}{$p$ for trend } \\
\hline & $\leq 60$ & $>60-65$ & $>65-70$ & $>70-75$ & $>75$ & \\
\hline Participants $(n)$ & 2,647 & 2,651 & 3,180 & 1,885 & 777 & \\
\hline Age (years), mean (SD) & $57.3(1.8)$ & $63.2(1.5)$ & $67.9(1.4)$ & $72.6(1.4)$ & $78.1(2.2)$ & $<0.0001$ \\
\hline Female, $n(\%)$ & $1,097(41.4)$ & $1,210(45.6)$ & $1,352(42.5)$ & $757(40.2)$ & $317(40.8)$ & 0.1195 \\
\hline $\begin{array}{l}\text { Age when diabetes first diagnosed (years), } \\
\text { mean (SD) }\end{array}$ & $49.9(6.0)$ & $55.4(6.3)$ & $59.9(6.6)$ & $64.2(6.9)$ & $69.2(7.7)$ & $<0.0001$ \\
\hline Diabetes duration (years), mean (SD) & $7.4(5.8)$ & $7.8(6.1)$ & $8.0(6.5)$ & $8.4(6.7)$ & $8.9(7.4)$ & $<0.0001$ \\
\hline \multicolumn{7}{|l|}{ Prior vascular disease } \\
\hline $\begin{array}{l}\text { History of major macrovascular } \\
\text { disease, } n(\%)\end{array}$ & $916(34.6)$ & $842(31.8)$ & $927(29.2)$ & $630(33.4)$ & $275(35.4)$ & 0.4840 \\
\hline History of myocardial infarction, $n(\%)$ & $58(2.2)$ & $75(2.8)$ & $101(3.2)$ & $88(4.7)$ & $47(6.0)$ & $<0.0001$ \\
\hline History of stroke, $n(\%)$ & $80(3.0)$ & $92(3.5)$ & $157(4.9)$ & $91(4.8)$ & $56(7.2)$ & $<0.0001$ \\
\hline $\begin{array}{l}\text { History of major microvascular } \\
\text { disease, } n(\%)\end{array}$ & $263(9.9)$ & $304(11.5)$ & $304(9.6)$ & $189(10.0)$ & $95(12.2)$ & 0.6787 \\
\hline History of macroalbuminuria, $n(\%)$ & $90(3.4)$ & $101(3.8)$ & $87(2.7)$ & $90(4.8)$ & $36(4.6)$ & 0.0645 \\
\hline $\begin{array}{l}\text { History of microvascular } \\
\text { eye disease, } n(\%)\end{array}$ & $184(7.0)$ & $215(8.1)$ & $224(7.0)$ & $109(5.8)$ & $63(8.1)$ & 0.4223 \\
\hline \multicolumn{7}{|l|}{ Blood glucose control } \\
\hline $\mathrm{HbA}_{1 \mathrm{c}}(\%)$, mean $(\mathrm{SD})$ & $7.7(1.7)$ & $7.6(1.6)$ & $7.4(1.5)$ & $7.4(1.5)$ & $7.2(1.4)$ & $<0.0001$ \\
\hline $\mathrm{HbA}_{1 \mathrm{c}}(\mathrm{mmol} / \mathrm{mol})$, mean $(\mathrm{SD})$ & $60.9(18.5)$ & $59.5(17.3)$ & $57.8(16.3)$ & $57.0(15.9)$ & $55.6(14.9)$ & $<0.0001$ \\
\hline $\mathrm{HbA}_{1 \mathrm{c}}(\%)$, median (IQR) & $7.4(6.5,8.6)$ & $7.2(6.5,8.4)$ & $7.2(6.4,8.1)$ & $7.1(6.4,8.0)$ & $7.0(6.4,7.8)$ & \\
\hline $\mathrm{HbA}_{1 \mathrm{c}}(\mathrm{mmol} / \mathrm{mol})$, median (IQR) & $57.4(47.5,70.5)$ & $55.2(47.5,68.3)$ & $55.2(46.4,65.0)$ & $54.1(46.4,63.9)$ & $53.0(46.4,61.7)$ & \\
\hline Fasting blood glucose (mmol/l), mean (SD) & $8.8(3.0)$ & $8.6(2.8)$ & $8.4(2.7)$ & $8.2(2.6)$ & $8.1(2.4)$ & $<0.0001$ \\
\hline \multicolumn{7}{|l|}{ Other major risk factors } \\
\hline Systolic blood pressure (mmHg), mean (SD) & $140.7(20.8)$ & $143.9(20.9)$ & $145.4(21.3)$ & $149.6(22.1)$ & $150.8(22.2)$ & $<0.0001$ \\
\hline $\begin{array}{l}\text { Diastolic blood pressure }(\mathrm{mmHg}) \\
\text { mean }(\mathrm{SD})\end{array}$ & $83.1(10.9)$ & $80.9(10.7)$ & $79.7(10.8)$ & $79.6(10.9)$ & $78.1(10.9)$ & $<0.0001$ \\
\hline $\begin{array}{l}\text { History of currently treated } \\
\text { hypertension, } n(\%)\end{array}$ & $1,760(66.5)$ & $1,823(68.8)$ & $2,198(69.1)$ & $1,322(70.1)$ & $552(71.0)$ & 0.0025 \\
\hline Current smoking, $n(\%)$ & $712(26.9)$ & $430(16.2)$ & $345(10.8)$ & $150(7.9)$ & $45(5.8)$ & $<0.0001$ \\
\hline Total cholesterol (mmol/l), mean (SD) & $5.3(1.3)$ & $5.3(1.2)$ & $5.1(1.2)$ & $5.1(1.1)$ & $5.1(1.1)$ & $<0.0001$ \\
\hline LDL-cholesterol (mmol/l), mean (SD) & $3.2(1.1)$ & $3.2(1.1)$ & $3.1(1.0)$ & $3.0(1.0)$ & $3.1(1.0)$ & $<0.0001$ \\
\hline HDL-cholesterol (mmol/l), mean (SD) & $1.2(0.3)$ & $1.3(0.4)$ & $1.3(0.4)$ & $1.3(0.3)$ & $1.3(0.3)$ & $<0.0001$ \\
\hline Triacylglycerol (mmol/l), mean (SD) & $2.2(1.5)$ & $2.0(1.4)$ & $1.9(1.1)$ & $1.8(1.0)$ & $1.7(0.9)$ & $<0.0001$ \\
\hline $\begin{array}{l}\text { Urinary albumin:creatinine } \\
\text { ratio (mg/mmol), mean }(\mathrm{SD})\end{array}$ & $6.1(12.9)$ & $6.1(13.6)$ & $5.1(10.8)$ & $6.7(14.6)$ & $6.8(14.9)$ & 0.3313 \\
\hline $\begin{array}{l}\text { Urinary albumin:creatinine ratio }(\mathrm{mg} / \mathrm{mol}) \text {, } \\
\text { median (IQR) }\end{array}$ & $1.7(0.8,4.9)$ & $1.7(0.8,4.4)$ & $1.6(0.8,3.9)$ & $1.9(0.9,4.7)$ & $1.8(0.8,5.0)$ & \\
\hline Microalbuminuria, $n(\%)$ & $727(27.5)$ & $655(24.7)$ & $776(24.4)$ & $489(25.9)$ & $210(27.0)$ & 0.4274 \\
\hline Serum creatinine $(\mu \mathrm{mol} / \mathrm{l})$, mean $(\mathrm{SD})$ & $81.5(25.0)$ & $84.5(23.2)$ & $87.1(23.2)$ & $91.0(24.8)$ & $97.4(36.2)$ & $<0.0001$ \\
\hline BMI $\left(\mathrm{kg} / \mathrm{m}^{2}\right)$, mean $(\mathrm{SD})$ & $29.0(5.7)$ & $28.4(5.4)$ & $28.1(5.0)$ & $28.1(4.7)$ & $27.7(4.5)$ & $<0.0001$ \\
\hline Waist circumference $(\mathrm{cm})$, mean $(\mathrm{SD})$ & $99.1(14.2)$ & $97.9(13.3)$ & $98.4(12.8)$ & $98.8(12.2)$ & $98.8(11.9)$ & 0.8800 \\
\hline
\end{tabular}

IQR, interquartile range

models were further adjusted for mean $\mathrm{HbA}_{1 \mathrm{c}}$ level before the index event, the associations remained evident, except for that between duration of diabetes and macrovascular events, which became marginally non-significant (ESM Table 4).

No interaction was observed between the effects of age or age at diagnosis and diabetes duration on the risks of macrovascular events and all-cause death (all $p$ for interaction
$>0.098$, Tables 3 and 4). Across all strata, older age, older age at diagnosis and longer diabetes duration increased the risks of macrovascular events and all-cause death (Figs 2a, b and $3 a, b)$.

When participants with a history of macrovascular disease at baseline were excluded from analyses, the results were unchanged (ESM Table 5). 
Table 2 Baseline characteristics by strata of diabetes duration

\begin{tabular}{|c|c|c|c|c|c|}
\hline \multirow[t]{2}{*}{ Characteristic } & \multicolumn{4}{|c|}{ Diabetes duration (years) } & \multirow[t]{2}{*}{$p$ for trend } \\
\hline & $0-5$ & $>5-10$ & $>10-15$ & $>15$ & \\
\hline Participants $(n)$ & 4,824 & 3,005 & 1,985 & 1,324 & \\
\hline Age (years), mean (SD) & $65.6(6.4)$ & $65.8(6.3)$ & $65.5(6.3)$ & $67.0(6.4)$ & $<0.0001$ \\
\hline Female, $n(\%)$ & $2,016(41.8)$ & $1,293(43.0)$ & $891(44.9)$ & $533(40.3)$ & 0.6836 \\
\hline Age when diabetes first diagnosed (years), mean (SD) & $63.1(6.6)$ & $57.7(6.6)$ & $52.8(6.4)$ & $46.5(7.4)$ & $<0.0001$ \\
\hline \multicolumn{6}{|l|}{ Prior vascular disease } \\
\hline History of major macrovascular disease, $n(\%)$ & $1,566(32.5)$ & $996(33.1)$ & $570(28.7)$ & $456(34.4)$ & 0.6619 \\
\hline History of myocardial infarction, $n(\%)$ & $135(2.8)$ & $103(3.4)$ & $70(3.5)$ & $61(4.6)$ & 0.0015 \\
\hline History of stroke, $n(\%)$ & $161(3.3)$ & $158(5.3)$ & $85(4.3)$ & $72(5.4)$ & 0.0007 \\
\hline History of major microvascular disease, $n(\%)$ & $362(7.5)$ & $278(9.3)$ & $269(13.6)$ & $246(18.6)$ & $<0.0001$ \\
\hline History of macroalbuminuria, $n(\%)$ & $140(2.9)$ & $104(3.5)$ & $90(4.5)$ & $70(5.3)$ & $<0.0001$ \\
\hline History of microvascular eye disease, $n(\%)$ & $229(4.7)$ & $185(6.2)$ & $189(9.5)$ & $192(14.5)$ & $<0.0001$ \\
\hline \multicolumn{6}{|l|}{ Blood glucose control } \\
\hline $\mathrm{HbA}_{1 \mathrm{c}}(\%)$, mean $(\mathrm{SD})$ & $7.2(1.4)$ & $7.6(1.5)$ & $7.8(1.6)$ & $7.9(1.7)$ & $<0.0001$ \\
\hline $\mathrm{HbA}_{1 \mathrm{c}}(\mathrm{mmol} / \mathrm{mol})$, mean $(\mathrm{SD})$ & $55.5(15.8)$ & $59.9(16.8)$ & $61.9(17.8)$ & $62.3(18.4)$ & $<0.0001$ \\
\hline $\mathrm{HbA}_{1 \mathrm{c}}(\%)$, median (IQR) & $6.9(6.3,7.8)$ & $7.3(6.6,8.4)$ & $7.5(6.7,8.6)$ & $7.5(6.7,8.6)$ & \\
\hline $\mathrm{HbA}_{1 \mathrm{c}}(\mathrm{mmol} / \mathrm{mol})$, median (IQR) & $51.9(45.3,61.7)$ & $56.3(48.6,68.3)$ & $58.5(49.7,70.5)$ & $58.5(49.7,70.5)$ & \\
\hline Fasting blood glucose (mmol/l), mean (SD) & $8.0(2.5)$ & $8.8(2.8)$ & $9.0(3.0)$ & $8.9(3.1)$ & $<0.0001$ \\
\hline \multicolumn{6}{|l|}{ Other major risk factors } \\
\hline Systolic blood pressure (mmHg), mean (SD) & $144.2(21.3)$ & $145.4(21.4)$ & $145.3(21.6)$ & $146.5(22.7)$ & 0.0005 \\
\hline Diastolic blood pressure (mmHg), mean (SD) & $81.2(10.9)$ & $80.9(10.9)$ & $80.0(10.8)$ & $79.0(11.2)$ & $<0.0001$ \\
\hline History of currently treated hypertension, $n(\%)$ & $3,260(67.6)$ & $2,110(70.2)$ & $1,365(68.8)$ & $918(69.3)$ & 0.1562 \\
\hline Current smoking, $n(\%)$ & $895(18.6)$ & $443(14.7)$ & $222(11.2)$ & $122(9.2)$ & $<0.0001$ \\
\hline Total cholesterol (mmol/l), mean (SD) & $5.3(1.3)$ & $5.3(1.2)$ & $5.1(1.2)$ & $5.1(1.1)$ & 0.0046 \\
\hline LDL-cholesterol (mmol/l), mean (SD) & $3.2(1.1)$ & $3.2(1.1)$ & $3.1(1.0)$ & $3.0(1.0)$ & 0.0022 \\
\hline HDL-cholesterol (mmol/1), mean (SD) & $1.2(0.4)$ & $1.3(0.4)$ & $1.3(0.4)$ & $1.3(0.3)$ & 0.0296 \\
\hline Triacylglycerol (mmol/l), mean (SD) & $2.2(1.5)$ & $2.0(1.4)$ & $1.9(1.1)$ & $1.8(1.0)$ & $<0.0001$ \\
\hline Urinary albumin:creatinine ratio (mg/mol), mean (SD) & $5.1(11.7)$ & $5.9(12.6)$ & $6.7(14.5)$ & $7.8(15.7)$ & $<0.0001$ \\
\hline Urinary albumin:creatinine ratio (mg/mol), median (IQR) & $1.5(0.7,3.8)$ & $1.7(0.8,4.7)$ & $1.8(0.9,4.9)$ & $2.1(1.0,5.9)$ & \\
\hline Microalbuminuria, $n(\%)$ & $1,133(23.5)$ & $801(26.7)$ & $519(26.1)$ & $404(30.5)$ & $<0.0001$ \\
\hline Serum creatinine $(\mu \mathrm{mol} / \mathrm{l})$, mean $(\mathrm{SD})$ & $85.7(23.8)$ & $86.2(23.6)$ & $87.0(29.9)$ & $89.6(27.2)$ & $<0.0001$ \\
\hline BMI $\left(\mathrm{kg} / \mathrm{m}^{2}\right)$, mean (SD) & $28.9(5.2)$ & $28.4(5.0)$ & $27.7(5.2)$ & $27.3(5.3)$ & $<0.0001$ \\
\hline Waist circumference $(\mathrm{cm})$, mean $(\mathrm{SD})$ & $99.6(13.1)$ & $98.8(13.2)$ & $96.8(13.1)$ & $96.7(12.5)$ & $<0.0001$ \\
\hline
\end{tabular}

$\mathrm{IQR}$, interquartile range

Microvascular events After base adjustment for randomised treatments, age at diagnosis and diabetes duration were associated with risk of microvascular events $(p<0.0001)$ but age was not ( $p=0.2889)$ (Tables 3 and 4, Fig. 1g-i). After further adjustment for baseline $\mathrm{HbA}_{1 \mathrm{c}}$ level, diabetes duration continued to be associated with risk of microvascular events $(p<0.0001$, Table 4$)$ but age at diagnosis was not $(p=0.2882$, Table 4). For each 5 year increase in diabetes duration, the multiple adjusted risk of microvascular events was increased by $28 \%$ (Table 3 ).

When the components of the microvascular outcome (new or worsening retinopathy and new or worsening nephropathy) were examined separately, the associations were consistent except that age was inversely associated with new or worsening retinopathy, such that after base and further adjustment for baseline $\mathrm{HbA}_{1 \mathrm{c}}$, older age was significantly associated with lower risk of retinopathy (ESM Table 3 ).

An interaction was observed between the effects of age or age at diagnosis and diabetes duration on the risk of microvascular events (both $p$ for interaction $<0.05$ ). Overall, for every 5 year increase in age or age at diagnosis, the effect of a 5 year increase in diabetes duration was reduced, with greater risks of microvascular events observed in those who were younger rather than older for the same duration of diabetes 
Table 3 Hazard ratios of adverse outcomes associated with a 5 year increase in age or duration of diabetes

\begin{tabular}{|c|c|c|c|c|c|}
\hline \multirow{3}{*}{$\begin{array}{l}\text { Effect of a } 5 \text { year } \\
\text { increase in exposure }\end{array}$} & \multicolumn{5}{|l|}{ Adjustments } \\
\hline & \multicolumn{2}{|l|}{ Base adjustment } & \multicolumn{2}{|c|}{ Base plus baseline $\mathrm{HbA}_{1 \mathrm{c}}$} & \multirow[b]{2}{*}{ Interaction $p$ value } \\
\hline & $\operatorname{HR}(95 \% \mathrm{CI})^{\mathrm{a}}$ & $p$ value & $\mathrm{HR}(95 \% \mathrm{CI})$ & $p$ value & \\
\hline Macrovascular events & & & & & 0.8079 \\
\hline Age & $1.32(1.26,1.38)$ & $<0.0001$ & $1.33(1.27,1.39)$ & $<0.0001$ & \\
\hline Diabetes duration & $1.17(1.12,1.22)$ & $<0.0001$ & $1.13(1.08,1.17)$ & $<0.0001$ & \\
\hline All-cause death & & & & & 0.6256 \\
\hline Age & $1.55(1.48,1.63)$ & $<0.0001$ & $1.56(1.48,1.64)$ & $<0.0001$ & \\
\hline Diabetes duration & $1.21(1.15,1.26)$ & $<0.0001$ & $1.15(1.10,1.20)$ & $<0.0001$ & \\
\hline Microvascular events & & & & & 0.0024 \\
\hline Age & $0.97(0.93,1.02)$ & 0.1962 & $0.98(0.93,1.02)$ & 0.2889 & \\
\hline Diabetes duration & $1.31(1.26,1.36)$ & $<0.0001$ & $1.28(1.23,1.33)$ & $<0.0001$ & \\
\hline
\end{tabular}

${ }^{\mathrm{a}}$ Adjusted for randomised blood pressure and glucose treatment

(Tables 3 and 4). However, when the associations were examined in those with short duration of diabetes ( $0-5$ years), there was a weak positive relationship between age or age at diagnosis and microvascular events, whereas in those with long duration of diabetes $(>10$ years) there was a clear negative relationship between age or age at diagnosis and microvascular events (Figs 2c, 3c).

When participants with a history of microvascular disease at baseline where excluded from analyses, the results were unchanged (ESM Table 5).

Competing risks In analyses taking account of all-cause death as a potential competing risk, the results for macrovascular and microvascular events (ESM Fig. 1) were almost identical to those from the primary analysis (Fig. 1).

\section{Discussion}

The new data presented here from a very large and diverse population of people with type 2 diabetes demonstrate that age or age at diagnosis of diabetes and diabetes duration are independently associated with the risk of macrovascular complications and death, whereas only diabetes duration was independently associated with the risk of microvascular complications. We report no interaction between the associations between age or age at diagnosis and diabetes duration on the risk of macrovascular events and death but a clear interaction between the associations between age or age at diagnosis and diabetes duration on the risk of microvascular events. Older age or age at diagnosis and longer diabetes duration proportionally increased the risk of macrovascular events and death,

Table 4 Hazard ratios of adverse outcomes associated with a 5 year increase in age at first diagnosis of diabetes or duration of diabetes

\begin{tabular}{|c|c|c|c|c|c|}
\hline \multirow[t]{3}{*}{ Effect of a 5 year increase in exposure } & \multicolumn{5}{|l|}{ Adjustments } \\
\hline & \multicolumn{2}{|l|}{ Base adjustment } & \multicolumn{2}{|c|}{ Base plus baseline $\mathrm{HbA}_{1 \mathrm{c}}$} & \multirow[b]{2}{*}{ Interaction $p$ value } \\
\hline & $\operatorname{HR}(95 \% \mathrm{CI})^{\mathrm{a}}$ & $p$ value & $\mathrm{HR}(95 \% \mathrm{CI})$ & $p$ value & \\
\hline Macrovascular events & & & & & 0.0982 \\
\hline Age at diagnosis & $1.06(1.03,1.10)$ & 0.0007 & $1.33(1.27,1.39)$ & $<0.0001$ & \\
\hline Diabetes duration & $1.17(1.12,1.22)$ & $<0.0001$ & $1.49(1.41,1.58)$ & $<0.0001$ & \\
\hline All cause death & & & & & 0.3919 \\
\hline Age at diagnosis & $1.14(1.10,1.18)$ & $<0.0001$ & $1.56(1.48,1.64)$ & $<0.0001$ & \\
\hline Diabetes duration & $1.21(1.15,1.26)$ & $<0.0001$ & $1.78(1.68,1.90)$ & $<0.0001$ & \\
\hline Microvascular events & & & & & 0.0164 \\
\hline Age at diagnosis & $0.84(0.81,0.86)$ & $<0.0001$ & $0.98(0.93,1.02)$ & 0.2882 & \\
\hline Diabetes duration & $1.31(1.26,1.36)$ & $<0.0001$ & $1.25(1.18,1.32)$ & $<0.0001$ & \\
\hline
\end{tabular}

${ }^{a}$ Adjusted for randomised blood pressure and glucose treatment 
Fig. 1 Cumulative incidence of events by 5 year strata of age at baseline $(\mathbf{a}, \mathbf{d}, \mathbf{g})$, age at diagnosis of diabetes $(\mathbf{b}, \mathbf{e}, \mathbf{h})$ and duration of diabetes $(\mathbf{c}, \mathbf{f}, \mathbf{i})$
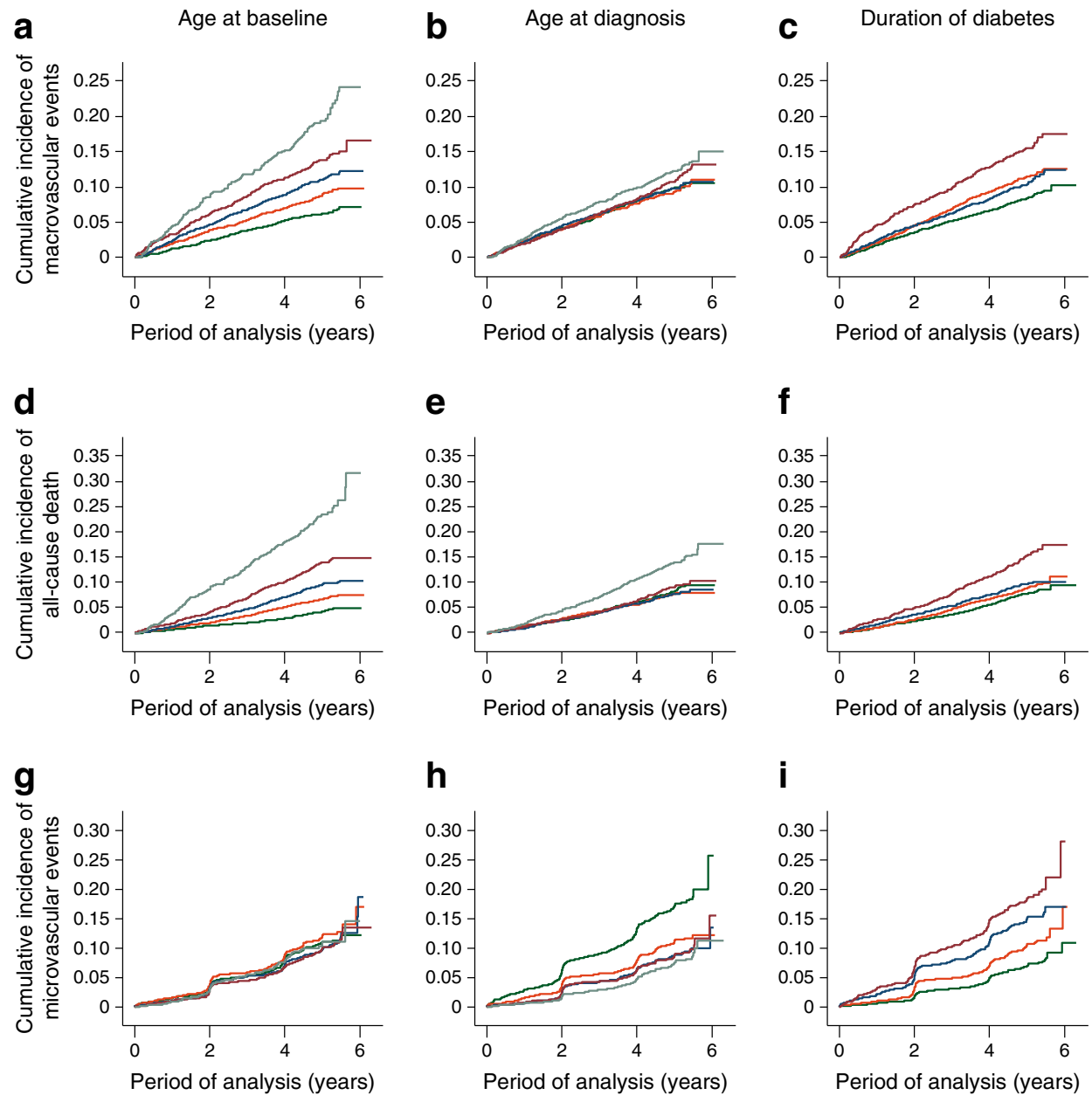

Age in years:

Age diagnosed in years:

i

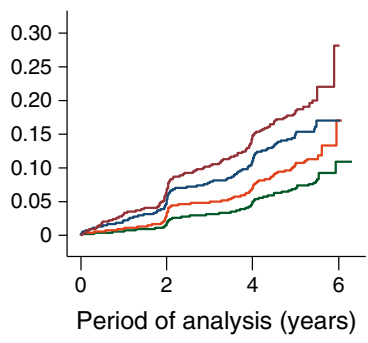

Diabetes duration in years:

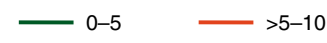

with the greatest risks observed in the oldest age groups with the longest duration of diabetes. By contrast, the adverse effects of longer diabetes duration on the risk of microvascular events were reduced with older age or age at diagnosis, such that the greatest risks of microvascular events were observed in the youngest age groups with the longest duration of diabetes.

The most likely explanation for the findings is that macrovascular events occur commonly in the general population and are strongly age dependent. We might thus expect the risk of macrovascular events to be related to age or age at diagnosis of diabetes, with an added risk conferred by duration of diabetes. By contrast, microvascular events occur more commonly in populations with diabetes and the risk of these events might thus be expected to be predominantly related to duration of diabetes.

Our findings are consistent with those of two previous studies $[12,13]$. Krolewski et al showed that microvascular eye lesions occurred in people with type 1 diabetes after sufficient intensity and duration of hyperglycaemia, and that duration was more important than intensity, provided that the intensity exceeded some threshold [12]. Jerneld and Algvere reported that retinopathy in insulin-treated patients correlated with duration of diabetes but not age at onset of diabetes [13]. Given that the diagnosis of type 2 diabetes is based on a glucose threshold at which the risk of retinopathy is substantively increased [14], it is reassuring that in our study age at diagnosis and diabetes duration were related to risk of microvascular events albeit with the effect of age at diagnosis accounted for by glycaemic control.

Our data further suggest that both the intensity of hyperglycaemia and a more susceptible microvasculature may explain the greater risk of microvascular complications in younger than older people with type 2 diabetes. In support, higher on average $\mathrm{HbA}_{1 \mathrm{c}}$ and fasting glucose levels were observed in the younger age groups despite on average shorter diabetes duration. Clearly, when type 2 diabetes occurs in younger people, good glycaemic control appears to be less often achieved. Alternatively, individuals who develop type 2 diabetes at a younger age may have a different phenotype (a combination of insulin resistance and a loss of beta cells) to 
a

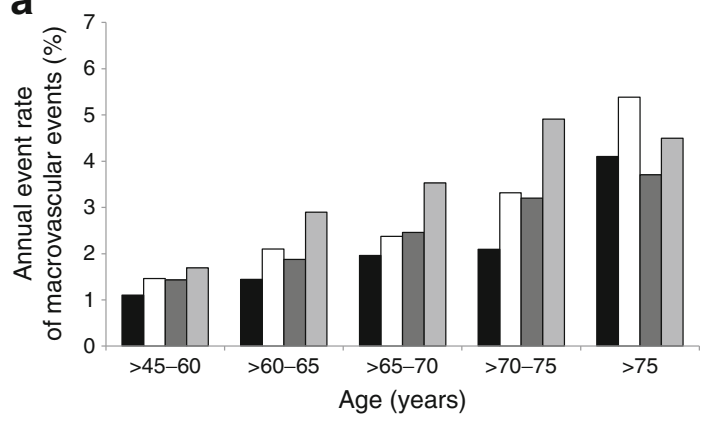

b

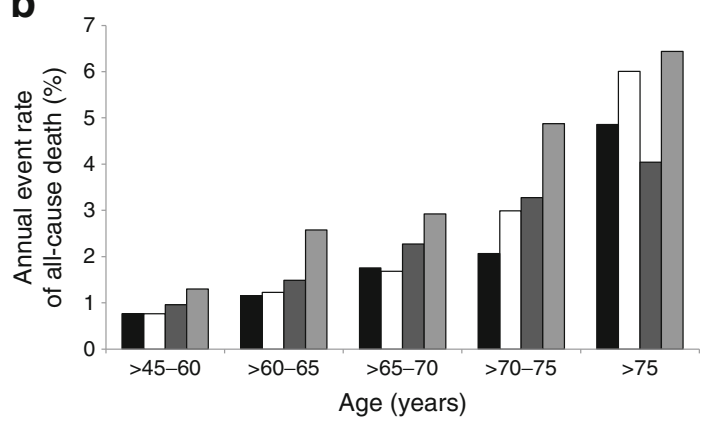

C

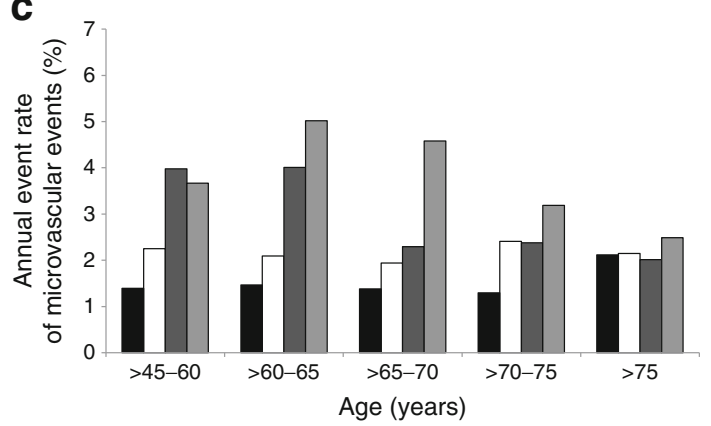

Fig. 2 Annual rates of macrovascular events (a), all-cause death (b) and microvascular events (c) by 5 year strata of age and duration of diabetes. Diabetes duration: black bars, $0-5$ years; white bars, $>5-10$ years; dark grey bars, $>10-15$ years; light grey bars, $>15$ years

those who develop type 2 diabetes at a more advanced age (who predominately have a loss of beta cells), such that worse glycaemic control and greater microvascular damage is experienced.

Our findings are consistent with data from the UKPDS, which reported no increase in prevalence of microvascular complications with older age at diagnosis [7]. Furthermore, a growing body of evidence suggests that type 2 diabetes diagnosed in young people is associated with a worse vascular risk profile, higher complication rates and worse prognosis than type 1 diabetes [15-17]. Our findings are also consistent with a recent pooled analysis, which reported that the proportional effects of vascular risk factors including systolic blood pressure and total cholesterol declined with age, such that the greatest relative risks were observed in the younger individuals aged 55-64 years [18].
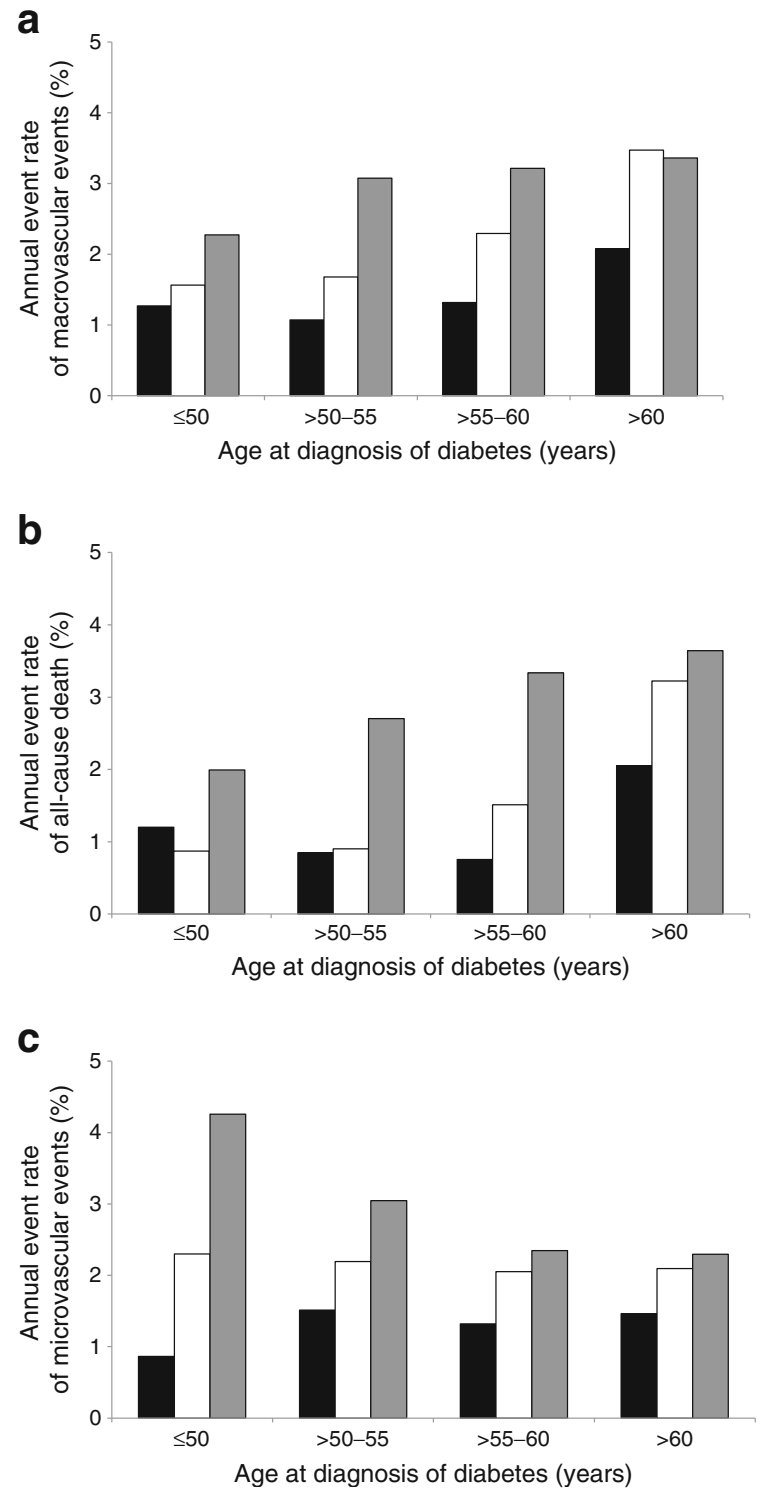

Fig. 3 Annual rates of macrovascular events (a), all-cause death (b) and microvascular events (c) by 5 year strata of age at diagnosis of diabetes and duration of diabetes. Diabetes duration: black bars, $0-5$ years; white bars, $>5-10$ years; grey bars, $>10$ years

Somewhat surprisingly in these observational analyses, age did not have a separate effect on the risk of microvascular events. One explanation may be that the effects of ageing on the microvasculature are masked by the preclinical and clinical phases of hyperglycaemia, which may have varied across the age groups. Another is that people with diabetes diagnosed later in life may not survive long enough for microvascular complications to develop and/or to become clinically manifest. Given that the findings were virtually identical when accounting for the effect of death as a competing risk event, this would seem unlikely.

These results support the need for more intensive surveillance and glycaemic control to prevent major microvascular 
complications in younger people living with type 2 diabetes. Given the legacy effects of intensive glucose control reported by the post-trial follow-up of the UKPDS cohort [19], and other studies that have suggested development of retinopathy as early as 7 years before the diagnosis of type 2 diabetes [20], a refocus towards intensive management of hyperglycaemia at diagnosis, particularly in younger people, may be warranted if the long-term risk of microvascular complications is to be minimised. With the increasing number of nonpharmacological and pharmacological approaches to improve glycaemic control this objective should be achievable [21].

With respect to macrovascular complications, our findings from patients with type 2 diabetes indicate that effective prevention requires vigilance at all stages of the disease and across all age groups. However, as the absolute event rates were highest in the older age groups, surveillance for macrovascular complications should be intensified with increasing age.

Our findings should be interpreted in light of the strengths and limitations of our study. The strengths include that the data were derived from a large cohort of ethnically diverse patients with type 2 diabetes who were prospectively followed for 5 years and had comprehensive ascertainment and adjudication of vascular complications. The limitations include the post hoc nature of the analysis and the highly selected study population, which was enriched with patients with complications or at high risk of cardiovascular disease and excluded patients on long-term insulin therapy. However, given the similarities between our cohort and other community-based observational cohorts of people with type 2 diabetes, we still believe our findings are somewhat generalisable [22]. Another limitation was our dependence on physician or patient report of age at first diabetes diagnosis (from which diabetes duration was determined). Given the wide range of diabetes duration represented in our cohort, this reporting may have been less accurate in those with longer diabetes duration than shorter diabetes duration. Moreover, we did not collect the original test results with which the diagnosis was made.

In conclusion, in patients with type 2 diabetes, age or age at diagnosis of diabetes and diabetes duration are independently associated with the risk of macrovascular complications and death. By contrast, only diabetes duration is independently associated with the risk of microvascular complications, and the effects of diabetes duration are greatest at younger rather than older ages. Intensive glycaemic control of young people diagnosed with type 2 diabetes is warranted early to minimise the risk of microvascular complications.

Funding ADVANCE was funded by grants from Servier and the National Health and Medical Research Council (NHMRC) of Australia (project grant ID 211086 and programme grant IDs 358395 and 571281). The sponsors had no role in data collection, data interpretation or the writing of the manuscript.
Duality of interest JC holds a research grant from Servier as principal investigator for ADVANCE. SZ was supported by a Heart Foundation of Australia Career Development Award. MW was supported by an NHMRC Senior Research Fellowship. SZ, JC, MC, MM and MW have received lecturing fees from Servier. All other authors declare that there is no duality of interest associated with their contribution to this manuscript.

Contribution statement All authors made substantial contributions to conception and design, acquisition of data, analysis and interpretation of data and drafting or revising of the manuscript for important intellectual content. All authors gave final approval of the version to be published. The first (SZ), second (MW) and last author (JC) had full access to the data of the study and take responsibility for the accuracy of the analysis and integrity of the work as a whole.

\section{References}

1. International Diabetes Federation (2013) IDF Diabetes Atlas, 6th edn. Brussels, Belgium: International Diabetes Federation. www. idf.org/diabetesatlas

2. Booth GL, Kapral MK, Fung K, Tu JV (2006) Relation between age and cardiovascular disease in men and women with diabetes compared with non-diabetic people: a population-based retrospective cohort study. Lancet 368:29-36

3. Vaccaro O, Eberly LE, Neaton JD, Yang L, Riccardi G, Stamler J, Multiple Risk Factor Intervention Trial Research Group (2004) Impact of diabetes and previous myocardial infarction on long-term survival: 25-year mortality follow-up of primary screenees of the Multiple Risk Factor Intervention Trial. Arch Intern Med 164:1438-1443

4. Fox CS, Sullivan L, D'Agostino RB Sr, Wilson PW (2004) The significant effect of diabetes duration on coronary heart disease mortality: the Framingham heart study. Diabetes Care 27:704-708

5. Wannamethee SG, Shaper AG, Whincup PH, Lennon L, Sattar N (2011) Impact of diabetes on cardiovascular disease risk and all-cause mortality in older men: influence of age at onset, diabetes duration, and established and novel risk factors. Arch Intern Med 171:404-410

6. Natarajan S, Liao Y, Sinha D, Cao G, McGee DL, Lipsitz SR (2005) Sex differences in the effect of diabetes duration on coronary heart disease mortality. Arch Intern Med 165:430-435

7. Davis TME, Stratton IM, Fox CJ, Holman RR, Turner RC (1997) UK Prospective Diabetes Study 22: effect of age at diagnosis on diabetic tissue damage during the first 6 years of NIDDM. Diabetes Care 20: 1435-1441

8. Patel A, MacMahon S, Chalmers J et al (2008) Intensive blood glucose control and vascular outcomes in patients with type 2 diabetes. N Engl J Med 358:2560-2572

9. Patel A, MacMahon S, Chalmers J et al (2007) Effects of a fixed combination of perindopril and indapamide on macrovascular and microvascular outcomes in patients with type 2 diabetes mellitus (the ADVANCE trial): a randomised controlled trial. Lancet 370:829-840

10. ADVANCE Management, Committee (2001) Study rationale and design of ADVANCE: action in diabetes and vascular disease - preterax and diamicron MR controlled evaluation. Diabetologia 44:1118-1120

11. Fine JP, Gray RJ (1999) A proportional hazards model for the subdistribution of a competing risk. J Am Stat Assoc 94:496-509

12. Krolewski AS, Warram JH, Rand LI, Kahn CR (1987) Epidemiologic approach to the etiology of type I diabetes mellitus and its complications. N Engl J Med 317:1390-1398

13. Jerneld B, Algvere P (1986) Relationship of duration and onset of diabetes to prevalence of diabetic retinopathy. Am J Ophthalmol 102: 431-437

14. Gabir M, Hanson RL, Dabelea D, Imperatore G, Roumain J, Bennett PH, Knowler WC (2000) Plasma glucose and prediction of 
microvascular disease and mortality. Evaluation of 1997 American Diabetes Association and 1999 World Health Organization criteria for diagnosis of diabetes. Diabetes Care 23:1113-1118

15. Eppens MC, Craig ME, Cusumano J et al (2006) Prevalence of diabetes complications in adolescents with type 2 compared with type 1 diabetes. Diabetes Care 29:1300-1306

16. Copeland KC, Zeitler P, Geffner M et al (2011) Characteristics of adolescents and youth with recent-onset type 2 diabetes: the today cohort at baseline. J Clin Endocrinol Metab 96:159167

17. Constantino MI, Molyneaux L, Limacher-Gisler F et al (2013) Longterm complications and mortality in young-onset diabetes: type 2 diabetes is more hazardous and lethal than type 1 diabetes. Diabetes Care 36:3863-3869

18. Singh GM, Danaei G, Farzadfar F et al (2013) The age-specific quantitative effects of metabolic risk factors on cardiovascular diseases and diabetes: a pooled analysis. PLoS One 8:e65174. doi: 10.1371/journal.pone.0065174

19. Holman RR, Paul SK, Bethel MA, Matthews DR, Neil A (2008) 10-year follow-up of intensive glucose control in type 2 diabetes. N Engl J Med 359:1577-1589

20. Harris MI, Klein R, Welborn TA, Knuiman MW (1992) Onset of NIDDM occurs at least 4-7 yr before clinical diagnosis. Diabetes Care 15:815-819

21. Inzucchi SE, Bergenstal RM, Buse JB et al (2012) Management of hyperglycaemia in type 2 diabetes: a patient-centered approach. Position statement of the American Diabetes Association (ADA) and the European Association for the Study of Diabetes (EASD). Diabetologia 55:1577-1596

22. Chalmers J, Arima H (2010) Importance of blood pressure lowering in type 2 diabetes: focus on ADVANCE. J Cardiovasc Pharmacol 55: $340-547$ 